\title{
Cold storage of diapausing larvae and post-storage performance of adults in the blowfly Lucilia sericata (Diptera: Calliphoridae)
}

\author{
Aoi Ichikawa, Motohiro Ikeda \& Shin G. Goto
}

\begin{tabular}{|c|l|}
\hline Citation & Applied Entomology and Zoology. 55(3); 321-327 \\
\hline Issue Date & $2020-08$ \\
\hline Published & $2020-04-22$ \\
\hline Type & Journal Article \\
\hline Textversion & Author \\
\hline Rights & $\begin{array}{l}\text { This is a post-peer-review, pre-copyedit version of an article published in Applied } \\
\text { Entomology and Zoology. The final authenticated version is available online at: } \\
\text { https://doi.org/10.1007/s13355-020-00685-8. } \\
\text { See Springer Nature terms of reuse. } \\
\text { https://www.springer.com/gp/open-access/publication-policies/aam-terms-of-use }\end{array}$ \\
\hline DOI & \begin{tabular}{l}
$10.1007 /$ s13355-020-00685-8 \\
\hline
\end{tabular}
\end{tabular}

Self-Archiving by Author(s)

Placed on: Osaka City University Repository

Ichikawa, A., Ikeda, M. \& Goto, S.G. Cold storage of diapausing larvae and post-storage performance of adults in the blowfly Lucilia sericata (Diptera: Calliphoridae). Applied Entomology and Zoology. 55, 321-327 (2020). doi:10.1007/s13355-020-00685-8 


\section{Cold Storage of Diapausing Larvae and Post-Storage}

Performance of Adults in the Blowfly Lucilia sericata

\section{(Diptera: Calliphoridae)}

Aoi Ichikawa ${ }^{1,3}$, Motohiro Ikeda ${ }^{1,3}$, Shin G. Goto ${ }^{2, *}$

${ }^{1}$ Department of Biology, Faculty of Science, Osaka City University, Japan;

${ }^{2}$ Department of Biology and Geosciences, Graduate School of Science, Osaka City

University, Japan;

${ }^{3}$ These authors contributed equally

${ }^{*}$ Correspondence

Graduate School of Science, Osaka City University,

3-3-138 Sugimoto, Sumiyoshi-ku, Osaka 558-8585, Japan

Tel. +81-6-6605-2573

Fax. $+81-6-6605-2522$

shingoto@osaka-cu.ac.jp

ORCID: 0000-0002-4431-7531

p. 1 


\section{Abstract}

A worldwide decline in the number of managed honeybee Apis mellifera Linnaeus (Hymenoptera: Apidae) colonies has increased our reliance on alternative insects for crop pollination. Costs of large-scale rearing and storage are among the major obstacles limiting the use of other insect species for pollination services. Recently, the blowfly Lucilia sericata (Meigen) (Diptera: Calliphoridae) has been identified as a potential alternative to the honeybee; development of storage techniques for this species would significantly improve its commercial viability as a managed pollinator. In this study, we investigated the effects of diapause and cold storage on $L$. sericata for mass rearing. We found that diapausing larvae could be stored at $7.5^{\circ} \mathrm{C}$ for several months with low mortality. The effects of cold storage on adult emergence depended on the strain of the fly tested. Adult survival was comparable between directly developing flies and flies that underwent diapause and cold storage until day 15 post-emergence. Adult locomotor activity (essential for effective pollination) was comparable between direct development and cold storage treatments. Based on these results, we propose the implementation of diapause and cold storage in L. sericata mass production for pollination, although further improvements are needed. 
Keywords: blowfly, cold storage,diapause, pollination

Running title: Cold storage of a diapausing blowfly

p. 3 


\section{Introduction}

Animal pollination is an important ecosystem service (Ollerton et al. 2011); insect pollination is particularly important in agriculture as a means of increasing the yield and quality of many crops (Bartomeus et al. 2014; Klein et al. 2007). Globally, pollination has typically relied on the European honeybee, Apis mellifera Linnaeus (Hymenoptera: Apidae) (Calderone 2012; Delaplane and Mayer 2000; Hung et al. 2018). However, a worldwide decline in the number of managed honeybee colonies has increased our reliance on alternative pollinating insect species (Decourtye et al. 2019; Goulson et al. 2015; Larson et al. 2001; Potts et al. 2010; Rader et al. 2015).

The common green bottle fly Lucilia sericata (Meigen) (Diptera: Calliphoridae), is a blowfly that plays an important role as a model insect in both pure (Alqurashi et al. 2019; Komo et al. 2020; Podhorna et al. 2018; Rhinesmith-Carranza et al. 2018) and applied sciences (Barroso et al. 2014; Chophi et al. 2019; Lihou and Wall 2019; Parry et al. 2019; Stadler et al. 2020). This species has also emerged as a valuable managed pollinator of commercial crops such as strawberry (Hanada et al. 2016; Herrmann et al. 2019; Yanagi et al. 2017), onion (Currah and Ockendon 1983, 1984), and mango (Dag and Gazit 2000; Mohsen 2019) in some countries. In particular, strawberry pollination efficiency of L. sericata is comparable to that of 
honeybees (Hanada et al. 2016), while onion pollination by L. sericata is even more effective than by honeybees in a colder climate (Currah and Ockendon 1983, 1984).

Lucilia sericata is easily reared and commercially available for various crop pollination services and medical use (maggot debridement therapy) (Hanada et al. 2016; Inouye et al. 2015; Stadler 2020). However, the cost and effort required to rear these flies in large numbers is a major obstacle to their efficient and widespread adoption as pollinators. The need to develop a technique enabling the storage of mass-reared insects and control their developmental timing to meet demands is a vital issue in the field of beneficial insect population management (Denlinger 2008). Implementing diapause may be the most efficient means of solving this problem.

For many insect species, reproductive or developmental processes are suppressed at times of the year when resources are lacking or environmental conditions are unfavorable (Danks 1987; Goto and Numata 2014; Tauber et al. 1986). Diapause, a hormonally-regulated developmental arrest, mitigates physiological stresses during such conditions and synchronizes active periods of insect life cycles with favorable conditions (Denlinger et al. 2012; Goto and Numata 2014). For L. sericata, larval diapause is initiated when short-day photoperiods are experienced by both the mother (parental generation) and the larvae themselves (Cragg 
and Cole 1952; Tachibana and Numata 2004b, c). Tachibana and Numata (2004a) showed that diapausing L. sericata larvae could withstand chilling at $7.5^{\circ} \mathrm{C}$ for 60 days; these larvae terminated diapause and pupated synchronously after transfer to normal (warm) rearing conditions. Additionally, larvae in diapause do not feed. Therefore, commercial fly suppliers should be able to maintain low-cost refrigerated fly stocks that will readily emerge as adults upon rewarming. However, successful implementation of this storage technique requires refrigerated flies to have adequate survival rates and normal adult locomotor activity; this is currently undetermined.

In the present study, we investigated the effects of diapause and cold storage on L. sericata performance to see their possible implications for mass rearing. We could effectively store larvae in diapause at $7.5^{\circ} \mathrm{C}$ for 4-5 months with little reduction in survival. The effects of cold storage on adult emergence depended on the strain of fly tested. Adult survival was comparable between flies developing directly (without diapause and cold storage) and those that experienced diapause and cold storage. Adult locomotor activity was nearly identical between direct development and diapause and cold storage treatments. Based on these results, we propose that diapause and cold storage are possible to be implemented in $L$. sericata mass production for pollination, although further improvement of the strategy is needed. 


\section{Materials and Methods}

\section{Insects}

The Japan Maggot Company, Co., Ltd (Okayama, Japan) kindly provided an L. sericata colony (JMC strain); a commercially available strain used for maggot debridement therapy, basic research (Kawabata et al. 2010; Mitsui et al. 2005; Nishijima et al. 2017) and strawberry pollination (Hanada et al. 2016; Yanagi et al. 2017). However, due to long-term management, the physiology of this strain may now be adapted to laboratory conditions and may not be fully representative of the species. Thus, an additional colony was studied, comprising individuals captured along the riverbank of the Yamato-gawa River $\left(34.6^{\circ} \mathrm{N}, 135.5^{\circ} \mathrm{E}\right)$ near the Osaka City University campus in 2017 (OCU strain).

Adults were reared at $25 \pm 1{ }^{\circ} \mathrm{C}$ under long-day conditions (LD 16:8 h) in plastic containers (15 cm diameter, $9 \mathrm{~cm}$ depth) covered with nylon netting and containing a piece of chicken liver for reproduction, a water bottle, and dry sugar cubes. Every 2-3 days, a fresh piece of liver was provided. Any deposited eggs were transferred to a section of liver in an aluminum dish placed on wood shavings; wandering larvae would crawl to this substrate to pupariate and pupate. 


\section{Diapause induction}

At emergence, adult flies were maintained at either $20 \pm 1{ }^{\circ} \mathrm{C}$ under diapause-averting long-day conditions (control) or diapause-inducing short-day conditions (LD 12:12 h) (Tachibana and Numata 2004a). New eggs were transferred on a section of liver and maintained at $15 \pm 1{ }^{\circ} \mathrm{C}$ under the same photoperiodic conditions as the parental generation as per Tachibana and Numata (2004c). Individuals remaining in the larval stage 27 days after cessation of feeding were considered to be in diapause, whereas those that pupariated were considered to be directly developing (not in diapause), as per Tachibana and Numata (2004c). We did not discriminate larval sexes.

\section{Larval cold storage, survival, and adult emergence}

Diapausing larvae were transferred to short-day conditions at 7.5 \pm $1{ }^{\circ} \mathrm{C}$ on the day of diapause assessment (day 27 post-feeding cessation) or kept in short-day conditions at $15 \pm 1^{\circ} \mathrm{C}$. Larvae, pupariated larvae (those that terminated diapause), and dead larvae were enumerated weekly. Pupariated larvae and dead larvae were removed immediately upon observation. Humidity was maintained in larval rearing containers by spraying the wood shavings weekly ( $\sim .5-1 \mathrm{~mL}$ of tap water).

Larvae stored at $7.5 \pm 1{ }^{\circ} \mathrm{C}$ under short-day conditions for 16 or 20 weeks were then transferred to long-day conditions at $25 \pm 1{ }^{\circ} \mathrm{C}$ to allow 
them to resume development. All emerging adults were enumerated and adult emergence (percentage) was calculated by dividing the number of adults by the number of larvae. Adults emerged within 2-6 days (Tachibana and Numata 2004a).

\section{Adult survival and locomotor activity}

Adult survival was compared between directly developing adults and adults kept in diapause at $7.5 \pm 1{ }^{\circ} \mathrm{C}$ for 16 weeks. Newly emerged adults were sexed; females and males were kept separately in plastic containers under long-day conditions at $25 \pm 1{ }^{\circ} \mathrm{C}$ with water and sugar. A maximum of fifteen adults were kept in each container. Surviving adults were enumerated every 15 days for 60 days.

Adult locomotor activity was assessed by actograph measurement 7-10 days after emergence as per Hamasaka et al. (2001). In brief, locomotor activity was recorded individually in a monitoring system comprising two cylindrical chambers. The activity chamber was flanked by a paired infrared emitter-detector (EESPW321, Omron, Kyoto, Japan). The number of times that a fly interrupted the infrared beam was recorded for 5 days. The first day of activity measurement was excluded due to fly hyperactivity after handling. 


\section{Statistics}

Survival on days 15 and 30, diapause incidence, and adult emergence were analyzed using Tukey-type multiple comparison test for proportions (Zar 2010). Locomotor activity data were analyzed using the Steel-Dwass test (Zar 2010).

\section{Results}

\section{Diapause induction}

Both L. sericata strains showed a clear photoperiodic response.

Larvae averted diapause and developed directly to adults under long-day conditions, whereas $82.5 \%$ and $69.0 \%$ of individuals in the JMC and OCU strains, respectively, entered diapause under short-day conditions (Fig. 1).

\section{Larval cold storage and survival and adult emergence}

At $15^{\circ} \mathrm{C}$, larvae began to terminate diapause within one or two weeks. All surviving larvae had terminated diapause and pupariated by 12 and 14 weeks for the JMC and OCU strains, respectively. At $7.5^{\circ} \mathrm{C}$, $93.3 \%$ of individuals remained as larvae with a $6.7 \%$ mortality rate by the end of 21 weeks in both strains (Fig. 2).

In the JMC strain, adult emergence following diapause and storage for 16 weeks (71.7\%) was comparable with that of directly 
developing adults (68.7 \%) (Fig. 3 left; Tukey-type multiple comparison test for proportions, $P>0.05)$. Emergence following diapause and storage for 20 weeks (51.8 \%) was significantly lower than that following diapause and storage for 16 weeks (Tukey-type multiple comparison test for proportions, $P<0.05)$, but it was insignificantly different from that of directly developing adults (Tukey-type multiple comparison test for proportions, $P>0.05)$.

In the OCU strain, adult emergence was significantly different among all three groups (Fig. 3 right; Tukey-type multiple comparison test for proportions, $P<0.05)$. Emergence was greatest in directly developing larvae $(83.4 \%)$, followed by larvae subjected to diapause and storage for 16 weeks (56.8 \%). The fewest emerging adults were observed for larvae subjected to diapause and storage for 20 weeks (33.8\%).

\section{Adult survival and locomotor activity}

Comparison of adult survival in directly developing flies and those that had experienced diapause and cold storage for 16 weeks demonstrated at least $90 \%$ adult survival at day 15 post-emergence irrespective of strain, sex, or developmental history and storage (Fig. 4a). After day 15, cumulative mortality increased for all groups such that fewer than $10 \%$ had survived by day 60 . For males on day 30 , directly developing flies had higher cumulative survival (50.0-63.3\%) than cold- 
stored flies (26.7-37.5\%), however, these differences were insignificant (Tukey-type multiple comparison test for proportions, $P>0.05$ ). By day 45 , fewer than $5 \%$ of males had survived. The trend was similar in females; directly developing JMC flies had significantly greater cumulative survival at day $30(80.0 \%)$ compared to either strain of cold-stored flies (25.0$30.8 \%$ ), with directly developing OCU flies exhibiting intermediate survival (56.7 \%). By day 45, directly developing JMC females were the only surviving group, exhibiting $27.7 \%$ survival that diminished to $6.7 \%$ by day 60 .

Diapause and cold storage during the larval stage did not negatively affect locomotor activity of adults (Fig. 4b). Locomotor activity in males of both strains was equivalent among directly developing flies and flies cold-stored for 16 or 20 weeks (Steel-Dwass test, $P>0.05$ ). In females, adult locomotor activity for cold-stored flies was either higher than or comparable to activity in directly developing flies (Steel-Dwass test).

\section{Discussion}

One of the greatest challenges facing the insect industry is to develop a method for storing beneficial insects without significantly decreasing their survival rate and performance (Colinet and Boivin 2011; 
Denlinger 2008). Implementation of diapause to improve insect cold storage has previously been proposed in the mass production of several species (Chen et al. 2013; Colinet and Boivin 2011; Gosterit and Gurel 2009; Tauber et al. 1993; Rinehart et al. 2013). This study shows that diapausing L. sericata larvae can be stored at a low temperature for 16-20 weeks with low larval mortality. This is substantially longer than previously demonstrated (Tachibana and Numata 2004a, c). Cold-stored L. sericata larvae terminated diapause and emerged as adults after transfer to a warm rearing temperature; these adults survived for at least 15 days with low mortality and showed a level of activity comparable to that of directly developing adults. These results highlight the potential for diapause and cold storage to improve $L$. sericata mass rearing, although there are several issues to be addressed prior to commercial implementation.

Although we adopted the most effective diapause-inducing environmental conditions that were reported previously (Tachibana and Numata 2004c), diapause incidence was not as high as 100\%, meaning not all individuals could be stored. It is therefore important to adopt shorter photoperiods and lower temperatures to increase the incidence of diapause. Other issues identified in this study were the negative effects of diapause and cold storage on both adult emergence and survival. Similar negative effects have also been observed in other species (Bradshaw et al. 1998; Ellers and van Alphen 2002; Matsuo 2006; Sadakiyo and Ishihara 
2012a, b). To mitigate this in L. sericata, optimal conditions should be determined by testing not only a broader range of cold storage temperatures and durations but also thermal acclimation in both generations (Colinet and Boivin 2011; Tougeron 2019). Constant low temperature (CLT) has long been used for cold storage for the sake of simplicity in a wide variety of insects, however recent studies show that exposing insects to fluctuating temperature (FT) significantly reduces cold-induced mortality when compared with CLT (Colinet et al. 2015, 2018). Leopold et al. (1998) reported that survival of L. sericata pupae exposed to FT $\left(10{ }^{\circ} \mathrm{C}\right.$ storage with a weekly 4-h recovery period at $\left.25{ }^{\circ} \mathrm{C}\right)$ was four times higher than that of pupae exposed to CLT. Furthermore, Rinehart et al. (2013) reported that implementing an FT regime dramatically increased the survival of cold-stored alfalfa leafcutting bee, Megachile rotundata (Fabricius) (Hymenoptera: Megachilidae), effectively extending their shelf life. Maternal thermal acclimation is also important to address. Coleman et al. (2014) showed that diapausing larvae of the blowfly Calliphora vicina Robineau-Desvoidy (Diptera: Calliphoridae) produced by adults acclimated to $15^{\circ} \mathrm{C}$ were more cold-tolerant than those produced by adults acclimated to $20^{\circ} \mathrm{C}$.

In this study, we found intraspecific variation in the effects of cold storage on adult emergence (the OCU strain was affected more than the JMC strain), potentially due to variation in energy reserve accumulation 
between strains (Ohtsu et al. 1992; Costanzo et al. 2013). Therefore, selection of the strain suitable for cold storage should be considered in future research, along with optimal storage duration. In general, a longer storage period lowers post-storage performance (Beekman et al. 1998; Ellers and van Alphen 2002; Matsuo 2006; Sadakiyo and Ishihara 2012a, b). Thus, it is important to determine precisely how much of reduction in performance is acceptable in the commercial implementation of diapause and cold storage.

The ability to store diapausing insects for weeks or months would allow suppliers to accumulate stocks during periods of low demand and/or in anticipation of high demand. As diapausing individuals are typically non-feeding, cost and effort to maintain them are low. Insects that enter quiescence during cold storage are ideal, as they readily resume development when required for pollination. Lucilia sericata is therefore a promising species for use in the pollination industry, and we invite further studies to optimize the diapause and cold storage techniques necessary to improve flexibility and efficiency in its mass production.

\section{Acknowledgements}

We would like to express our appreciation to Dr. Lauren E. Des Marteaux for critical reading of the draft version of this manuscript and English 
editing. We also thank Editage (www.editage.co.jp) for English editing. The study was, in part, supported by the Japan Society for the Promotion of Science (JSPS) KAKENHI, Grant-in-Aid for Scientific Research (B) (Grant Number 19H02971) to SGG.

\section{Author contributions}

Conceptualization: SGG; Methodology: SGG; Formal analysis and investigation: AI, MI, \& SGG; Writing - original draft preparation: SGG; Writing - review and editing: AI, MI, \& SGG.

\section{Conflict of interest}

The authors declare that they have no conflict of interest.

\section{References}

Alqurashi S, English S, Wall R (2019) Nutritional requirements for reproduction and survival in the blowfly Lucilia sericata. Med Vet Entomol. https://doi.org/10.1111/mve.12425

Bartomeus I, Potts SG, Steffan-Dewenter I, Vaissière BE, Woyciechowski M, Krewenka KM, Tscheulin T, Roberts SPM, Szentgyörgyi H, Westphal S, Bommarco R (2014) Contribution of insect pollinators to crop yield 
and quality varies with agricultural intensification. PeerJ 2:e328. https://doi.org/10.7717/peerj.328

Barroso FG, de Haro C, Sánchez-Muros MJ, Venegas E, Martínez-Sánchez A, Pérez-Bañón C (2014) The potential of various insect species for use as food for fish. Aquaculture 422:193-201 https://doi.org/10.1016/j.aquaculture.2013.12.024

Beekman M, van Stratum P, Lingeman R (1998) Diapause survival and post-diapause performance in bumblebee queens (Bombus terrestris). Entomol Exp Appl 89:207-214. https://doi.org/10.1046/j.15707458.1998.00401.x

Bradshaw WE, Armbruster PA, and Holzapfel CM (1998) Fitness consequences of hibernal diapause in the pitcher-plant mosquito, Wyeomyia smithii. Ecology 79:1458-1462. https://doi.org/10.2307/176758 Calderone NW (2012) Insect pollinated crops, insect pollinators and US agriculture: Trend analysis of aggregate data for the period 1992-2009. PLoS ONE 7:e37235. https://doi.org/10.1371/journal.pone.0037235

Chen H, Zhang H, Zhu KY, Throne J (2013) Performance of diapausing parasitoid wasps, Habrobracon hebetor, after cold storage. Biol Contr 64:186-194. https://doi.org/10.1016/j.biocontrol.2012.11.007

Chophi R, Sharma S, Sharma S, Singh R (2019) Forensic entomotoxicology: Current concepts, trends and challenges. J Forensic Leg Med 67:28-36. https://doi.org/10.1016/j.jflm.2019.07.010 
Coleman PC, Bale JS, Hayward SAL (2014) Cross-generation plasticity in cold hardiness is associated with diapause, but not the non-diapause developmental pathway, in the blow fly Calliphora vicina. J Exp Biol 217:1454-1461. https://doi.org/10.1242/jeb.098053

Colinet H, Boivin G (2011) Insect parasitoids cold storage: A comprehensive review of factors of variability and consequences. Biol Contr 58:83-95. https://doi.org/ 10.1016/j.biocontrol.2011.04.014

Colinet H, Sinclair BJ, Vernon P, Renault D (2015) Insects in fluctuating thermal environments. Annu Rev Entomol 60:123-140. https://doi.org/10.1146/annurev-ento-010814-021017

Colinet H, Rinehart JP, Yocum GD, Greenlee KJ (2018) Mechanisms underpinning the beneficial effects of fluctuating thermal regimes in insect cold tolerance. J Exp Biol 221:jeb164806. https://doi.org/10.1242/jeb.164806

Costanzo JP, do Amaral MC, Rosendale AJ, Lee RE Jr (2013) Hibernation physiology, freezing adaptation and extreme freeze tolerance in a northern population of the wood frog. J Exp Biol 216:3461-3473. https://doi.org/10.1242/jeb.089342

Cragg JB, Cole P (1952) Diapause in Lucilia sericata (MG.) Diptera. J Exp Biol 29:600-604

Currah L, Ockendon DJ (1983) Onion pollination by blowflies and honeybees in larger cages. Ann Appl Biol 103:497-506. 
https://doi.org/10.1111/j.1744-7348.1983.tb02789.x

Currah L, Ockendon DJ (1984) Pollination activity by blowflies and honeybees on onions in breeders' cages. Ann Appl Biol 105:167-176. https://doi.org/10.1111/j.1744-7348.1984.tb02812.x

Dag A, Gazit S (2000) Mango pollinators in Israel. J Appl Hort 2: 39-43.

Danks HV (1987) Insect Dormancy: An Ecological Perspective. Biological Survey of Canada, Ottawa.

Decourtye A, Alaux C, Le Conte Y, Henry M (2019) Toward the protection of bees and pollination under global change: present and future perspectives in a challenging applied science. Curr Opin Insect Sci 35:123-131. https://doi.org/10.1016/j.cois.2019.07.008

Delaplane KS, Mayer DF (2000) Crop Pollination by Bees. CABI Publishing, Oxon.

Denlinger DL (2008) Why study diapause? Entomol Res 38:1-9. https://doi.org/10.1111/j.1748-5967.2008.00139.x

Denlinger DL, Yocum GD, Rinehart JP (2012) Hormonal control of diapause. In: Gilbert LI (ed) Insect Endocrinology. Elsevier BV Academic Press, Waltham, pp.430-463. https://doi.org/10.1016/B978-012-384749-2.10010-X

Ellers J, van Alphen JJM (2002) A trade-off between diapause duration and fitness in female parasitoids. Ecol Entomol 27:279-284. https://doi.org/10.1046/j.1365-2311.2002.00421.x 
Gosterit A, Gurel F (2009) Effect of different diapause regimes on survival and colony development in the bumble bee, Bombus terrestris. J Apicult Res 48: 279-283. https://doi.org/10.3896/IBRA.1.48.4.08

Goto SG, Numata H (2014) Insect Photoperiodism. In: Hoffmann KH (ed) Insect Molecular Biology and Ecology. CRC Press, Boca Raton, pp.217244

Goulson D, Nicholls E, Botias C, Rotheray EL (2015) Bee declines driven by combined stress from parasites, pesticides, and lack of flowers. Science 347:1255957. https://doi.org/10.1126/science.1255957

Hamasaka Y, Watari Y, Arai T, Numata H, Shiga S (2001) Retinal and extraretinal pathways for entrainment of the circadian activity rhythm in the blow fly, Protophormia terraenovae. J Insect Physiol 47:867-875. https://doi.org/10.1016/S0022-1910(01)00059-2

Hanada A, Yoshida Y, Sato T, Goto T, Yasuba K-i, Tanaka Y (2016) Utilization of Phaenicia sericata Meig. (green blow fly) as an alternative pollinator to honey bee. Hort Res (Japan) 15:161-169. https://doi.org/10.2503/hrj.15.161 (in Japanese with English abstract) Herrmann JD, Beye H, de la Broise C, Hartlep H, Diekötter T (2019) Positive effects of the pollinators Osmia cornuta (Megachilidae) and Lucilia sericata (Calliphoridae) on strawberry quality. Arthropod-Plant Inte 13:71-77. https:/doi.org/10.1007/s11829-018-9636-7

Hung KJ, Kingston JM, Albrecht M, Holway DA, Kohn JR (2018) The p. 20 
worldwide importance of honey bees as pollinators in natural habitats.

Proc Biol Sci 285(1870) pii:20172140.

https://doi.org/10.1098/rspb.2017.2140

Inouye, DW, Larson BMH, Ssymank A, Kevan PG (2015) Flies and flowers

III: Ecology of foraging and pollination. J Poll Ecol 16:115-133.

https://doi.org/10.26786/1920-7603(2015)15

Kawabata T, Mitsui H, Yokota K, Ishino K, Oguma K, Sano S (2010)

Induction of antibacterial activity in larvae of the blowfly Lucilia

sericata by an infected environment. Med Vet Entomol 24:375-381.

https://doi.org/10.1111/j.1365-2915.2010.00902.x

Komo L, Hedouin V, Charabidze D (2020) Quickie well done: no evidence

of physiological costs in the development race of Lucilia sericata

necrophagous larvae. Physiol Entomol 45:30-37.

https://doi.org/10.1111/phen.12313

Klein A-M, Vaissière BE, Cane JH, Steffan-Dewenter I, Cunningham SA,

Kremen C, Tscharntke T (2007) Importance of pollinators in changing

landscapes for world crops. Proc R Soc B 274:303-313.

https://doi.org/10.1098/rspb.2006.3721

Larson BMH, Kevan PG, Inouye DW (2001) Flies and flowers: taxonomic

diversity of anthophiles and pollinators. Can Entomol 133:439-465.

https://doi.org/10.4039/Ent1334394

Leopold RA, Rojas RR, Atkinson PW (1998) Post pupariation cold storage 
of three species of flies: increasing chilling tolerance by acclimation and recurrent recovery peroids. Cryobiology 36:213-224. https://doi.org/10.1006/cryo.1998.2081

Lihou K, Wall R (2019) Sheep blowfly strike: the cost of control in relation to risk. Animal 13: 2373-2378. https://doi.org/10.1017/S1751731119000831

Matsuo Y (2006) Cost of prolonged diapause and its relationship to body size in a seed predator. Funct Ecol 20:300-306. https://doi.org/10.1111/j.1365-2435.2006.01097.x

Mitsui H, Kawabata T, Ugaki S, Ohsawa S, Fujii Y, Sano S (2005) Successful treatment of severe ischemic foot ulcer with sterile maggots: the first case in this country. Jpn J Vasc Surg 14:653-657

Mohsen AMA (2019) Survey of insect mango pollinators and the pollination occurrence of mango trees in relations to fruit yields. Curr Sci Int 8:245-251

Nishijima A, Yamamoto N, Yoshida R et al. (2017) Maggot debridement therapy for a patient with critical limb ischaemia and severe cardiac dysfunction: possibility of limb salvage. Case Reports Plast Surg Hand Surg 4:42-47. https://doi.org/10.1080/23320885.2017.1327322

Ohtsu T, Kimura MT, Hori SH (1992) Energy storage during reproductive diapause in the Drosophila melanogaster species group. J Comp Physiol B. 162:203-208. https://doi.org/10.1007/bf00357524 
Ollerton J, Winfree R, Tarrant S (2011) How many flowering plants are pollinated by animals? Oikos 120:321-326. https://doi.org/10.1111/j.1600-0706.2010.18644.x

Potts SG, Biesmeijier JC, Kremen C, Neumann P, Schweiger O, Kunin WE (2010) Global pollinator declines: trend, impacts and drivers. Trends Ecol Evol 25:345-353. https://doi.org/10.1016/j.tree.2010.01.007 Parry NJ, Pieterse E, Weldon CW (2019) Stocking rate and organic waste type affect development of three Chrysomya species and Lucilia sericata (Diptera: Calliphoridae): Implications for bioconversion. J Appl Entomol 144:94-108. https://doi.org/10.1111/jen.12712

Podhorna J, Aubernon C, Borkovcova M, Boulay J, Hedouin V, Vharabidze D (2018) To eat or get heat: Behavioral trade-offs between thermoregulation and feeding in gregarious necrophagous larvae. Insect Sci 25:883-893. https://doi.org/10.1111/1744-7917.12465

Rader R, Bartomeus I, Garibaldi LA et al. (2015) Non-bee insects are important contributors to global crop pollination. Proc Natl Acad Sci USA 113:146-151. https://doi.org/10.1073/pnas.1517092112 Rinehart JP, Yocum GD, Kemp WP, Greenlee KJ (2013) A fluctuating thermal regime improves long-term survival of quiescent prepupal Megachile rotundata (Hymenoptera: Megachilidae). J Econ Entomol 106:1081-1088. https://doi.org/10.1603/ec12486

Rhinesmith-Carranza J, Liu WQ, Tomberlin JK, Longnecker M, Tarone AM 
(2018) Impacts of dietary amino acid composition and microbial presence on preference and performance of immature Lucilia sericata (Diptera: Calliphoridae). Ecol Entomol 43:612-620.

https://doi.org/10.1111/een.12646

Sadakiyo S, Ishihara M (2012a) Cost of diapause on life-history traits under restricted resources in multivoltine bruchid Acanthoscelides pallidipennis (Coleoptera: Bruchidae). Ann Entomol Soc Am 105:422426. https://doi.org/10.1603/AN11109

Sadakiyo S, Ishihara M (2012b) Cost of male diapause indirectly affects female reproductive performance. Entomol Exp Appl 143:42-46. https://doi.org/10.1111/j.1570-7458.2012.01223.x

Stadler F (2020) The maggot therapy supply chain: a review of the literature and practice. Med Vet Entomol 34:1-9. https://doi.org/10.1111/mve.12397

Tachibana S-I, Numata H (2004a) Effects of temperature and photoperiod on the termination of larval diapause in Lucilia sericata (Diptera: Calliphoridae). Zoolog Sci 21:197-202. https://doi.org/10.2108/zsj.21.197

Tachibana S-I, Numata H (2004b) Maternal induction of larval diapause and its sensitive stage in the blow fly Lucilia sericata (Meigen) (Diptera: Calliphoridae). Entomol Sci 7:231-235. https://doi.org/10.1111/j.14798298.2004.00068.x 
Tachibana S-I, Numata H (2004c) Parental and direct effects of photoperiod and temperature on the induction of larval diapause in the blow fly Lucilia sericata. Physiol Entomol 29:39-44. https://doi.org/10.1111/j.0307-6962.2004.0360.x

Tauber MJ, Tauber CA, Gardescu S (1993) Prolonged storage of Chrysoperla carnea (Neuroptera: Chrysopidae). Environ Entomol 22:843-848. https://doi.org/10.1093/ee/22.4.843

Tauber MJ, Tauber CA, Masaki S (1986) Seasonal Adaptations of Insects. Oxford University Press, New York.

Tougeron K (2019) Diapause research in insects: historical review and recent work perspectives. Entomol Exp Appl 167:27-36.

https://doi.org/10.1111/eea.12753

Yanagi T, Miura H, Isobe S, Okuda N, Yoshida Y (2017) Effect of insect pollinator on inbreeding versus outbreeding in open pollinated strawberry seeds. Sci Hortic 215:112-116.

https://doi.org/10.1016/j.scienta.2016.12.015

Zar JH (2010) Biostatistical Analysis, 5th Edition, Prentice Hall, Upper Saddle River, NJ. 


\section{Figure legends}

Fig. 1 Incidence of diapause in two strains (JMC and OCU) of Lucilia sericata larvae reared under long-day and short-day conditions. Directly developing (Direct) individuals were those that pupariated, while diapausing larvae (Diapause) were those remaining in the larval stage 27 days after cessation of feeding

Fig. 2 Cumulative proportions of two strains (JMC and OCU) of Lucilia sericata larvae that remained as larvae, terminated diapause and thus pupariated, or died as larvae during storage under short-day conditions at $15{ }^{\circ} \mathrm{C}$ or $7.5^{\circ} \mathrm{C}$

Fig. 3 Adult emergence of two strains (JMC and OCU) of Lucilia sericata following diapause and storage for 16 (W16) or 20 weeks (W20) at $7.5{ }^{\circ} \mathrm{C}$. Directly developing (Direct) individuals were reared continuously at $25{ }^{\circ} \mathrm{C}$ under long-day conditions as a control. The emergence percentages of the two strains were analyzed separately by Tukey-type multiple comparison test for proportions. There is no significant difference between the values followed by the same lowercase letters $(P>0.05)$ 
Fig. 4 Survival and locomotor activity of two strains (JMC and OCU) of Lucilia sericata adults following diapause and storage at $7.5^{\circ} \mathrm{C}$. Directly developing (Direct) individuals were reared continuously at $25{ }^{\circ} \mathrm{C}$ under long-day conditions as a control. (a) Survival of adult males and females over 60 days. Closed and open circles denote directly developing JMC and OCU flies, respectively. Closed and open triangles respectively denote JMC and OCU flies subjected to diapause and cold for 16 weeks. $n=12-30$. There is no significant difference between the values followed by the same lowercase letters (Tukey-type multiple comparison test for proportions, $P$ $>0.05) ;$ n.s. indicates no statistically significant difference. (b) $\log _{10-}$ transformed locomotor activity of directly developing (Direct) adult flies, along with those subjected to diapause and cold for 16 (W16) and 20 (W20) weeks. $n=6-11$. There is no significant difference between the values followed by the same lowercase letters (Steel-Dwass test, $P>0.05$ ); n.s. indicates no statistically significant difference 


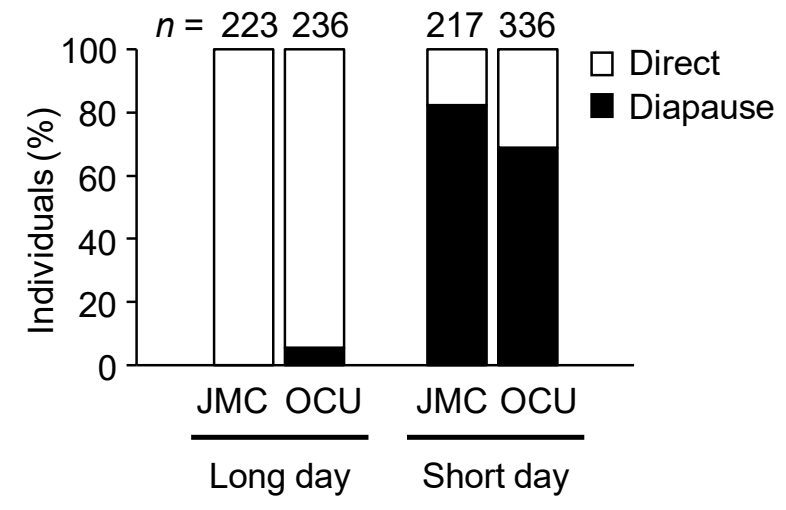

Fig. 1 

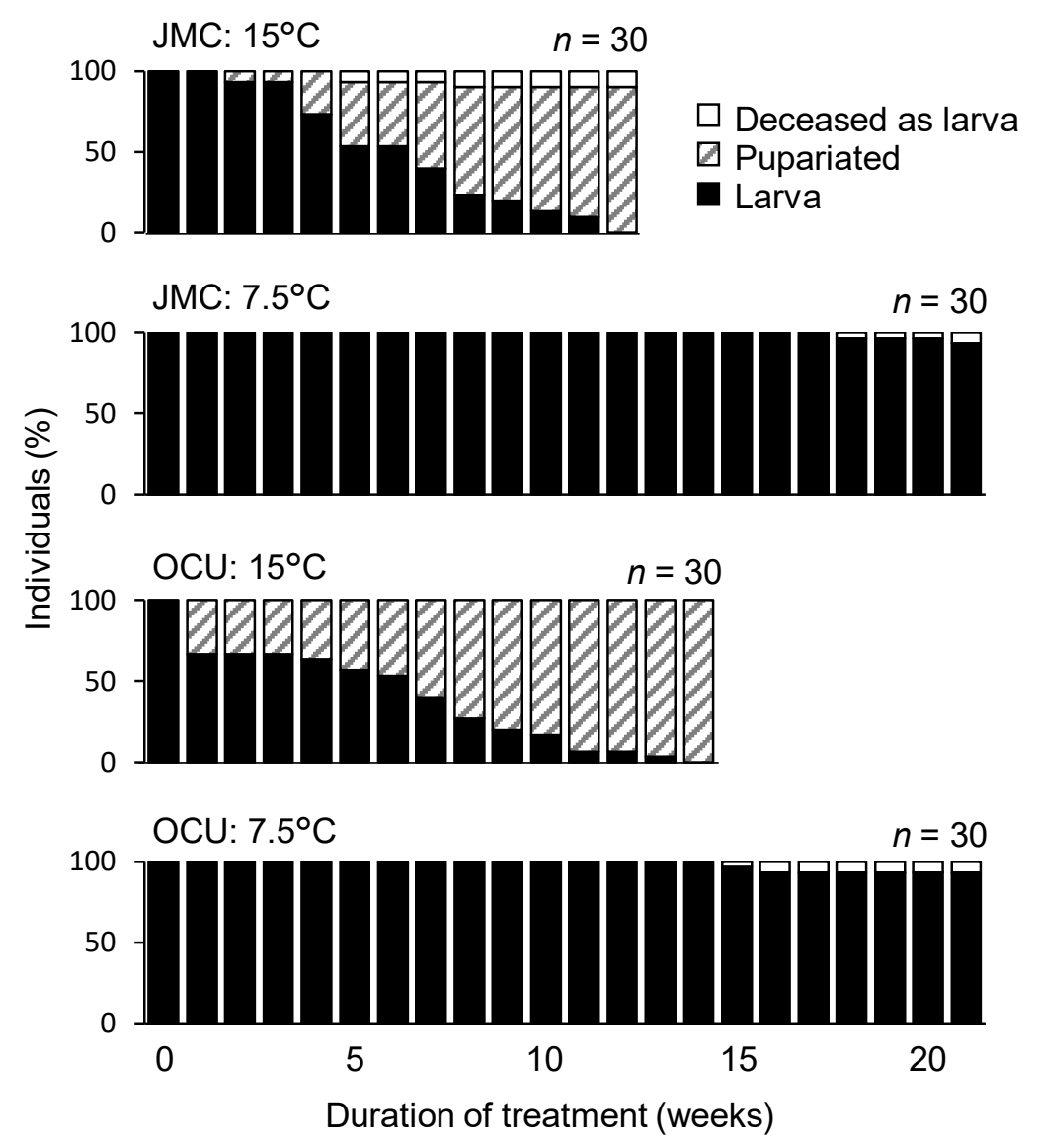

Fig. 2 
Fig. 3 
(a)

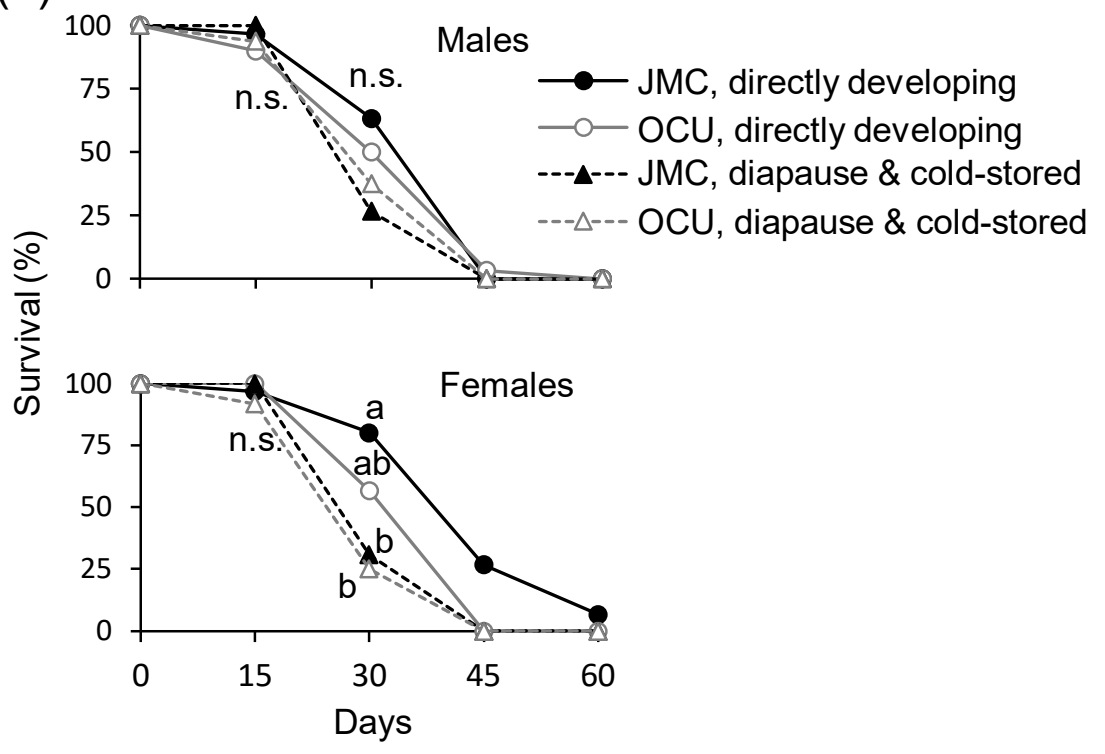

(b)

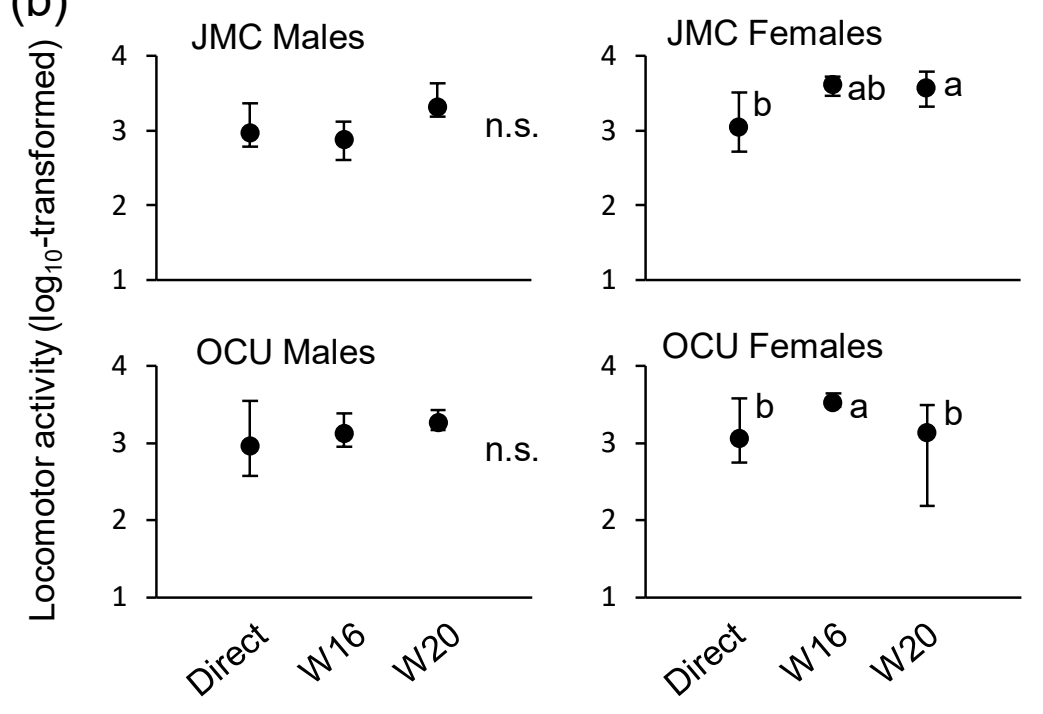

